\title{
Estimating the unknown quantitative information for residual TCE source and the residual source allocation using various tracer data at a DNAPL contaminated site, Korea
}

\author{
${ }^{1}$ SEONG-Sun LeE ${ }^{1}$, IL-RYOUNG CHO ${ }^{1}$, Dugin KAOWN ${ }^{1}$, \\ EUN-HEE $\mathrm{KOH}^{1}$ AND KANG-KUN LEE ${ }^{1 *}$ \\ ${ }^{1}$ School of Earth and Environmental Sciences, Seoul National \\ University, South Korea soon3311@snu.ac.kr, \\ violet96@snu.ac.kr, dugin1@snu.ac.kr, \\ eannara@snu.ac.kr, kklee@snu.ac.kr, (*correspondence: \\ kklee@snu.ac.kr)
}

Among partitioning tracers, noble gases have strength in identifying the fractionation processes due to its inertness. Thus, noble gases are often used to describe systems of Oil and natural gas reservoirs. In this study, analytical solution method which can assess and quantify the impacts of partial residual DNAPL source reduction by intensive remedial action performed in study site is used to estimate the unknown residual source mass and dissolved concentration using long-term monitoring data collected from 2009 to 2019 in the study site. Also, by applying the noble gas as a tracer, it was able to identify the partitioning processes between TCE and noble gases. Through analytical solution method based on the source zone monitoring data during about 11 years, initial dissolved concentration and residual mass of TCE at the time of spilled events can be roughly estimated $150 \mathrm{mg} / \mathrm{L}$ and $1000 \mathrm{~kg}$, respectively. However, after an intensive remedial action, these values dramatically decreased up to $0.45 \mathrm{mg} / \mathrm{L}$ and $33.07 \mathrm{~kg}$ and then it expected to be continuously decreased to $0.19 \mathrm{mg} / \mathrm{L}$ and $19.92 \mathrm{~kg}$ from the end of remedial actions to 2020 . From the results of noble gas analysis, it is identified that the distance from TCE source zone was divided into three groups from Zone 1 to 3 . Zone 1 is the closest area from the TCE main source, and are highly partitioned to TCE compared to other zones. It has been identified that Zone 3 does not accord with either of the fractionation lines and is more influenced by other mechnisms rather than partitioning to TCE. From the results of this study, it was able to estimate the unknown quantitative information of residual TCE source using analytical solution based on long-term monitoring data and noble gas tracer as the indicator of DNAPL contamination could be applied in allocating the DNAPL residual source. 